\title{
Adopting Rapid Prototyping Technology within Small and Medium-Sized Enterprises: The Differences between Reality and Expectation
}

\author{
Ahmed M. Romouzy-Ali, Siamak Noroozi, Philip Sewell, and Tania Humphries-Smith
}

\begin{abstract}
The aim of this paper is to study existing adoption of Rapid Prototyping (RP) technology within small- and medium sized enterprises (SMEs) in addition to measuring the need for this technology. This study adopted a mixed method approach involving a postal survey of $\mathbf{2 0 0}$ companies followed by in-depth semi-structure interviews with 10 SMEs generating qualitative data which scrutinised the state on the ground in depth. The barriers to $R P$ adoption were resistance to change, lack of resources, lack of professional qualifications and RP process limitation. Where RP was adopted the executive mangers stated that it is very effective across all of the associated aspects, however due to the barriers low levels of significance in adopting RP were revealed by SMEs not already using it. Consequently, whilst SMEs show negative response towards adopting RP technology, where they do so, they are satisfied with the outcomes. SMEs views about this barriers and the state of adoption generally are explored.
\end{abstract}

Index Terms-Rapid prototyping technology, Small and Medium Sized enterprises, change management research and development.

\section{INTRODUCTION}

Human evolution was founded on the basis of forming/shaping knowledge, and actually the narration of humankind civilisation has been boosted by the advancement of forming/shaping expertise[1]. To develop a new product, a prototype of a designed product or mechanism needs to be fabricated before the provision of enormous amounts of investment to new production machinery [2].

Before the 1990s, the industrialised societies had to waste significant time building prototypes of the products and mechanisms to test their performance [3]. The chase for lower operational costs and enhanced manufacturing competence has strained a great number of industrialised firms to adopt advanced manufacturing technology of a variety of processes [4].

Rapid Prototyping (RP) refers to the fabrication of a physical model from computer-Aided Design (CAD) data. $\mathrm{RP}$ is a relatively new technology that was first

Manuscript received May 14, 2012; revised June 13, 2012.

Ahmed M. Romouzy-Ali is with the Design Simulation Research Centre, School of Design, Engineering and Computing, Bournemouth University, United Kingdom and the Industrial Design Department, Faculty of Applied Arts, Helwan University, Egypt (e-mail: ahromouzy@ hotmail.com).

The other three authors are with the School of Design, Engineering and Computing, Bournemouth University, United Kingdom (e-mail: snoroozi@bournemouth.ac.uk; thumphril@bournemouth.ac.uk). commercialised by 3D Systems in 1987 [5]. What is commonly considered to be the first RP technique, Stereolithography (SLA), was developed by 3D Systems of Valencia, CA, USA. The company was founded in 1986, and since then, a number of different RP techniques have become available. RP potentially offers great benefits in terms of time and cost reduction as well as improved quality of the final product when used during a product development process [6]. RP has also been referred to as solid free-form manufacturing; computer automated manufacturing, and layered manufacturing (LM). RP has obvious use as a vehicle for visualisation. In addition, RP models can be used for testing, such as when an airfoil shape is put into a wind tunnel. RP models can be used to create male models for tooling, such as silicone rubber moulds and investment casts. In some cases, the RP part can be the final part, but typically the RP material is not strong or accurate enough. When the RP material is suitable, highly convoluted shapes (including parts nested within parts) can be produced because of the nature of RP.

This study is mainly focused on the adoption of RP within Small and Medium-sized Enterprises (SMEs). [7] States "SMEs are crucial in job creation, providing a 10\% increase since the start of the current economic crisis and helping to boost recovery in the United Kingdom". Statistics shows that there are 4.5 million small businesses in the UK, SMEs account for 99 per cent of all enterprise in the UK, 58.8 per cent of private sector employment and 48.8 per cent of private sector turnover [8]. [9] Describes the categories of SMEs as "Medium-sized enterprises are defined as enterprises which employ fewer than 250 persons and whose annual turnover total does not exceed 50 million euro or annual balance sheet total does not exceed 43 million euro. Small enterprises are defined as enterprises which employ fewer than 50 persons and whose annual turnover or annual balance sheet total does not exceed 10 million euro. Micro enterprises are defined as enterprises which employ fewer than 10 persons and whose annual turnover or annual balance sheet total does not exceed 2 million euro" (see fig. 1). Manufacturing has been developing over the years as different needs and technologies arise. The world of business is changing rapidly. The winds of globalisation have pushed SMEs to grapple with the changing needs of their customers. The customer of the twenty-first century, demands products and services that are fast, right, cheap and easy [4]. It is recognised that products launched before their competitors are commonly more profitable and enjoy a larger share of the market [2]. 


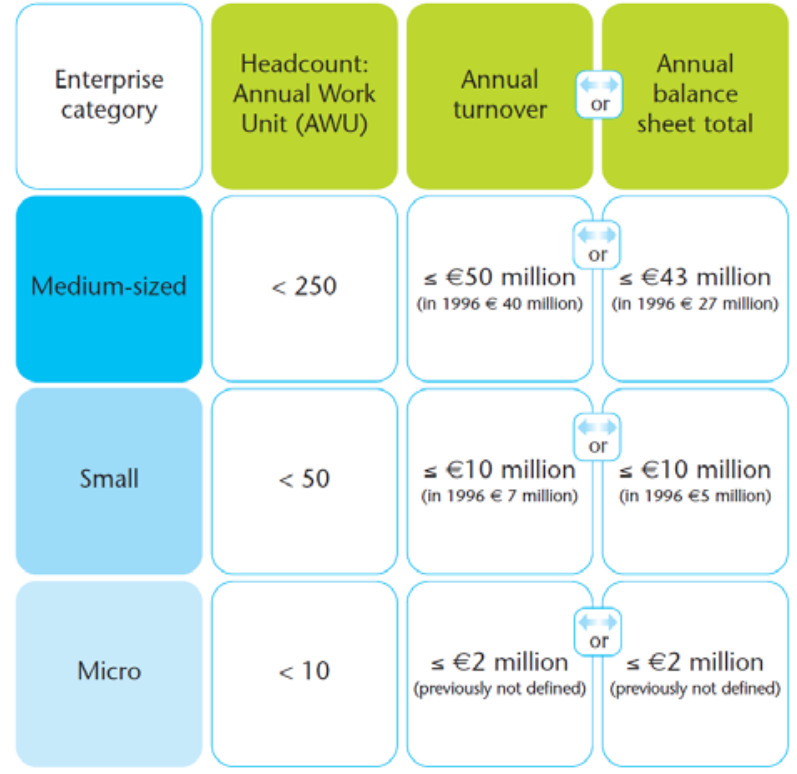

Fig. 1. SMEs threshold. source: [9].

In this day and age, stiff competition, technology advancement and the globalisations of markets, most of the companies have been forced to consider and implement a wide variety of innovative management philosophies, approaches, and techniques [10]. The aim of instigating the traditional manufacturing organisations to take on RP technology is to achieve competitiveness [3].

However, the most successful application to benefit from the RP begins with the correct adoption of the process, that makes the process procedure, as well as the right definition of prototype requirements, very important steps [11]. But the adoption must be preceded by confidence and a feasibility study to bring these technologies to manufacturing processes already in use to support the adoption of this decision.

\section{RESEARCH AND DEVELOPMENT (R\&D) WITHIN SMES}

As global manufacturing industries continue to undergo deep structural changes-which include the relocation not only of production, but also of related knowledge intensive activities such as R\&D and other professional services, governments throughout the world are increasingly devoting attention to the support of the national industrial activity [12]. The majority of big enterprises have Research and Development (R\&D) departments for bringing innovation projects to the consideration of top management and for facilitating their implementation. Large enterprises view SMEs as satellites that would rotate around them seeking revenue and possible profit [13]. Therefore SMEs must have the knowledge and full awareness of the constructive contribution that this new technology provides, especially when the size of the business is not comparable to the size of business within large companies that have inclusive independent departments for taking such decisions (see fig. 2) [14]. In the present era of globalisation SMEs should possess the ability to get the organisation to innovate quickly and produce an acceptable product and service to capture upcoming business opportunity [4].SMEs, on the other hand, over and over again do not have a proper procedure recognised [15], and $R \& D$ culture is absent due to financial constraints [16].

\section{THE ADOPTION OF RP WITHIN SMES}

Despite this significance, more SMEs continue to ignore the adoption of RP technology due to a range of barriers. This moderately -if not extremely- hinders the development as well as the competitiveness of SMEs. However given the industrial and economical significance of SMEs it would seem that RP technology has much to interest the industrial/manufacturing SMEs executive managers. Studies in this field have revealed that SMEs can be rich sources of innovation in relation to new technologies.

This discussion raises a number of relevant questions pertaining to SMEs and RP, which provided the focus for this study:

- Do SMEs adopt RP and if so what are SMEs actual RP adoption strategies?

- Where adopted, how successful is the RP technology perceived to be?

- Where not adopted, what are the barriers hindering the adoption of RP and what are the potential strategies to initiate a change management state to adopt RP?

Based on the UK regional development, the South West of England (SW) was selected as a representative SME sampling region, where the SW was found to be the most appropriate region for this particular study due to its growth and development rates. [7] Describes the SW as "SMEs in south-west England have the most optimistic outlook on growth out of all regions, followed by those in London and Wales".[17] Says "The South West continues to derive more employment and turnover from SMEs than any other region”.

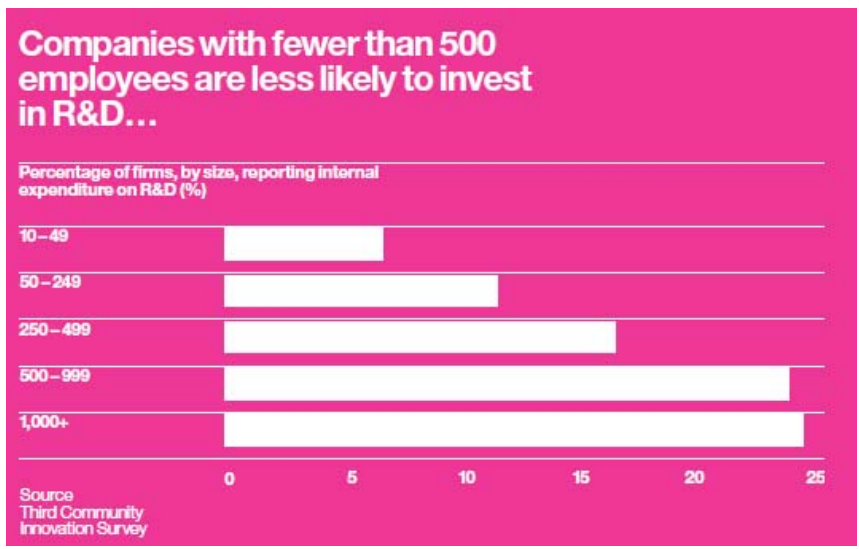

Fig. 2. Percentage of firms, by size, reporting internal expenditure on R\&D. source: [14]

\section{Methodology}

This study adopted a mixed-method research approach, so as to obtain data of appropriate scope and depth. A large scale postal survey of 200 SMEs in SW was conducted to recognise the adoption of RP technology and identify the barriers hindering the adoption of RP as well as prioritising them. This survey questions regarding RP were incorporated with other survey questions measuring the utilisation of change management culture within SMEs. 
This survey was followed by semi-structure in-depth face to face interviews with 10 SMEs executive managers at their business locations; this has provided more in detail exploration of the associated issues. These approach methods are outlined in more detail. The postal survey questions related to the following areas (see Table 1 ).

This postal self-reported structured survey was designed, piloted, analysed and conducted by the researcher. The survey was sent out with a pre-addressed/pre-stamped return envelope. The pilot phase involved random participants of the main sample. A new specific regional database was created for the design/industrial/manufacture SMEs involved in engineering processes. The data was collected from different sources such as online databases, yellow pages, telephones directories and paid databases. While creating the database it was taken into account that it should be random, heterogeneous and representative to guarantee the external validity, so the results can generalised. Out of the 55 returned surveys, 50 valid surveys were initially utilised in this study with a $28 \%$ response rate which is above the typical response rate for this type of survey.

Based on the literature findings, the typical response rate for strategic studies is $10-12 \%$ [18-23]. Those excluded were considerably incomplete questionnaires.

The second phase of the study was the semi-structure in-depth face to face interviews. The interview covered a range of related areas as follows:-

- The participant's level of education and responsibilities within the SME;

- New technologies adoption, and in particular RP technology within the SME;

- The extent to which he agrees with the first phase results, discussion about the barriers hindering the RP adoption;

- The visible significance of RP technology to the SME;

- The future plans or strategies to adopt RP within the companies

The interviews were aimed to scrutinise in depth the barriers that were identified and prioritised from the first phase of the methodology. The researcher conducted the interviews with the executive managers from 10 SMEs on their location across the SW. A confidentiality agreement was signed with the participants prior to each interview, and the interviews were digitally recorded and afterwards transcribed by the researcher. Using thematic analysis technique to analyse the transcripts, the researcher generated a list of representative codes to themes identified from the transcribed text. The interviews presented several themes all the way through the interpretation of the transcripts, which were revised in the analysis.

\begin{tabular}{|l|l|l|l|}
\hline \multicolumn{2}{l}{ TABLE I: THE POSTAL SURVEY QUESTIONS RELATED AREAS } \\
\hline \multirow{3}{*}{ Company Profile } & Significance of & Investment in & $\begin{array}{l}\text { RP technology adoption / } \\
\text { barriers to adoption within } \\
\text { the company }\end{array}$ \\
\cline { 2 - 3 } & $\begin{array}{l}\text { In-House Design Practices; In-House R\&D; RP Technology; } \\
\text { CAD; CNC machining; innovation processes }\end{array}$ \\
\hline
\end{tabular}

\section{FINDINGS}

\section{A. The Overall Technological Atmosphere}

With the aim of understanding of the internal overall technological atmosphere within SMEs, respondents were asked in the postal survey about the related product development issues in terms of significance and investment levels within their companies (see Figure 3). It was clearly seen that in-house design practices, in-house research and development as well as Computer Aided Design (CAD) to be very important with 82 percent suggesting it was very significant and 18 percent suggesting it was less/not significant. RP technology processes was seen to be less/not important with 70 percent suggesting it was less/not significant and 30 percent suggesting it was very significant, however Computer Numerical Control (CNC) was seen to be important with 60 percent suggesting it was very significant and 40 percent suggesting it was less/not significant. Respondents were also asked about the level of investment within their companies in the related issues, they indicated that they had moderate/heavy investments as to 42 percent for in-house design practises; 68 percent for in-house research and development, 48 percent for CAD, 26 percent for CNC and only 10 percent for RP technology processes.

\section{B. Barriers to Adopt RP Technology}

The results from the postal survey in relation to the barriers that hinder RP adoption show that 30 percent of the SME companies surveyed had used RP technology process. In the 70 percent of the sample which had never used any RP technology, the most common barriers were resistance to change (44 percent), lack of professional qualifications (36 percent), RP technology limitations (36 percent) and resistance to change (30 percent). While the results are not surprising, it is some of the first collected data to prioritise the barriers that hinder the adoption of RP technology within SMEs. This result suggests that SMEs are more likely to adopt RP on the event of overcoming these only four above mentioned barriers.

A similar more in-depth pattern of data was exposed in the interview findings. The content analysis of the transcribed interviews revealed five main themes:

Human development concerns: Generally the interviewees believed that to sustain a dedicated and stimulated business they need to develop their staff's skills, as these skills are the input in dealing with desired change. Although internal training is regularly implemented to address the development of employees with practical skills, the development of executive level is generally needed to a certain extent. Also most of the companies were facing serious challenges with regards to succession planning and the generation of senior executive managers. 


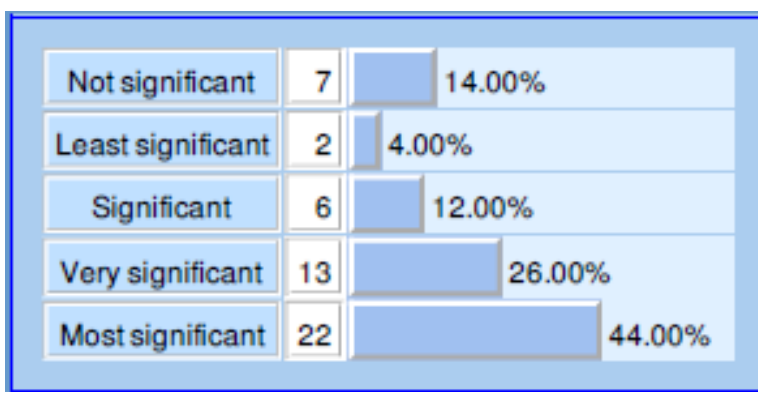

\begin{tabular}{|c|r||c|}
\hline No investment & 10 & $20.00 \%$ \\
\hline Slight investment & 9 & $18.00 \%$ \\
\hline No idea & 10 & $20.00 \%$ \\
\hline Moderate investment & 14 & $28.00 \%$ \\
\hline Heavy investment & 7 & $14.00 \%$ \\
\hline
\end{tabular}

In-House Design Practises

\begin{tabular}{|c|r||c|}
\hline Not significant & 7 & \multicolumn{2}{|l|}{$14.00 \%$} \\
\hline Least significant & 2 & \multicolumn{2}{|l|}{$4.00 \%$} \\
\hline Significant & 11 & $22.00 \%$ \\
\hline Very significant & 10 & $20.00 \%$ \\
\hline Most significant & 20 & \multicolumn{2}{|c|}{$40.00 \%$} \\
\hline
\end{tabular}

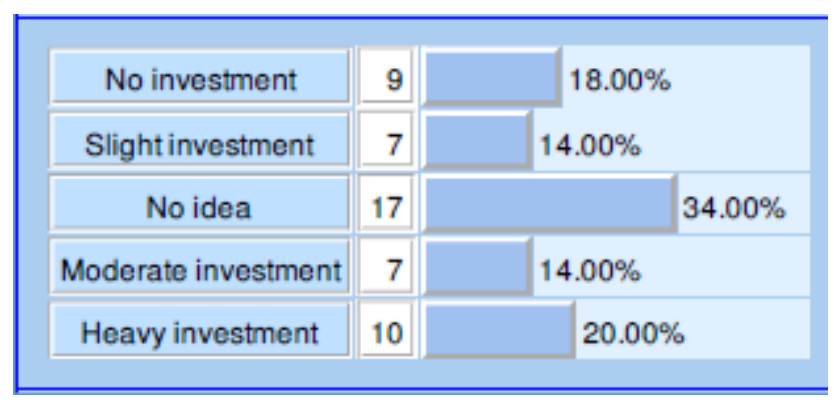

In-House Research and Development

\begin{tabular}{|c|c|c|c|}
\hline Not significant & 24 & & \\
\hline Least significant & 11 & & \\
\hline Significant & 6 & $22.00 \%$ \\
\hline Very significant & 6 & $12.00 \%$ \\
\hline Most significant & 3 & $6.00 \%$ \\
\hline
\end{tabular}

\begin{tabular}{|r|r|r|r|}
\hline No investment & 32 & & \\
\hline Slight investment & 7 & & $14.00 \%$ \\
\hline No idea & 6 & $12.00 \%$ \\
\hline Moderate investment & 3 & $6.00 \%$ \\
\hline Heavy investment & 2 & $4.00 \%$ \\
\hline
\end{tabular}

RP Technology Processes

\begin{tabular}{|c|c|c|c|}
\hline Not significant & 6 & \multicolumn{2}{|c|}{$12.00 \%$} \\
\hline Least significant & 3 & \multicolumn{2}{|l|}{$6.00 \%$} \\
\hline Significant & 4 & \multicolumn{2}{|l|}{$8.00 \%$} \\
\hline Very significant & 16 & \multicolumn{2}{|r|}{$32.00 \%$} \\
\hline Most significant & 21 & & $42.00 \%$ \\
\hline
\end{tabular}

\begin{tabular}{|c||r||c|}
\hline No investment & 7 & \multicolumn{2}{|c|}{$14.00 \%$} \\
\hline Slight investment & 4 & $8.00 \%$ \\
\hline No idea & 15 & $30.00 \%$ \\
\hline Moderate investment & 13 & $26.00 \%$ \\
\hline Heavy investment & 11 & $22.00 \%$ \\
\hline
\end{tabular}

Computer Aided Design (CAD)

\begin{tabular}{|c|r||c|}
\hline Not significant & 15 & $30.00 \%$ \\
\hline Least significant & 5 & $10.00 \%$ \\
\hline Significant & 6 & $12.00 \%$ \\
\hline Very significant & 11 & $22.00 \%$ \\
\hline Most significant & 13 & $26.00 \%$ \\
\hline
\end{tabular}

\begin{tabular}{|r|r||r|}
\hline No investment & 21 & \multicolumn{2}{|c|}{$42.00 \%$} \\
\hline Slight investment & 6 & $12.00 \%$ \\
\hline No idea & 10 & \multicolumn{2}{|c|}{$20.00 \%$} \\
\hline Moderate investment & 3 & $6.00 \%$ \\
\hline Heavy investment & 10 & $20.00 \%$ \\
\hline
\end{tabular}

Computer Numerical Control (CNC)

Fig. 3 Percentage of significance and level of investment within SMEs.

Strategic concerns: The interviewees viewed resistance to change in a negative way and nearly all agreed that in order to 
survive they must bring in change within their companies. All expressed a need for technological growth and saw it as input to long-term business survival. The majority were looking to obtain a technological development to improve productivity, effectiveness, competitiveness rather than normal organic growth.

Resources concerns: There was a common awareness of the importance of resources in SMEs, with regard to the financial resources in particular and the capability to deal with the current recession. Arguably that the SME executive needs to combine elements of both financial and management in their responsibility, and of the essential required skills, accountancy was deliberated as without a doubt the most significant. The ability to handle everyday budget concerns to think of the long-term financial flexibility of the company was seen as one of the major challenges.

$R P$ technology awareness: Most of the interviewees perceived RP technology with high level of awareness, as they demonstrated knowledge of the technology. Even though some of them showed a high confident level of knowledge regarding the RP technology, it was found that the executive managers are so reluctant when it comes to decision making level to deploy the RP technology or not. However some of them find outsourcing the RP technology is the right thing to do.

Independent concerns: A range of other matters were found to be independently affecting the SME's liaison with the outside world. Such as global competition from other countries like China, where the labour cost is far cheaper than UK to the extent of which they can't manage. Also knowledge transfer and the challenges associated with it, in addition to the difficulty of sustaining a state-of-the-art link in every relative field. What's more the governmental support which is insufficient plus the escalating trouble of rules and laws.

\section{DISCUSSION}

According to these results, the SMEs are functioning in very challenging internal and external surroundings. Human development within SMEs is currently a very high priority, as it will lead to new change management policies to be implemented in their sectors. This will unlock the barriers of resistance to change as well as the lack of professional qualifications as [15] said '...Most managerial positions at SMEs are acquired based on experience and lack professional qualifications...'. It is also not surprising that the most frequent barrier is lack of resources, because of which SMEs cannot take on RP technology due to the current internal and external financial constraints. RP is evidently seen as an appropriate process when related to the crucial dynamics on which the SMEs strategically perform '...Better technology, better tools may help SMEs but we should not miss the real opportunity of creating a new generation of SMEs with a strategic mindset...' [24].

The way towards a high level of awareness of the need for RP technology against the prioritised barriers is dependent on both prior research linked to SMEs and the provisional strategy to overcome these barriers as '...The obstacles may be clear, but that doesn't make them easy to address...' [16].
Despite the high volume of models and frameworks which point to a number of approaches to deploy RP technology, all approaches do not stand up because they are more generic in nature rather than specific in their customisation to this sector. This suggests that any new strategy attempts to help this specific sector of companies to overcome these barriers, should implement the four prioritised barriers as pillars on which the problems will be tackled. One implication of this is the need to boost awareness of the significance of involving the executive managers in any attempts in the forms of either Technology Transfer (TT) or Knowledge Transfer Partnership (KTP). This may be an involvement that will simply lead to establishment of a new RP technological culture with SMEs.

An optimistic unexpected result from this study is the fact that 30 percent of the sample has used RP technology to some extent, either onsite or by outsourcing. This has shown a great variation between reality and expectation, as it was expected from the literature that not only RP is absent but the whole culture of research and development is absent as [15] indicated '...R\&D culture at SMEs is absent due to financial constraints...'. With approximately one third of the sample having new technological adoption culture within their companies, the chances of more positive change management are more likely to happen rapidly. This underpins the influence associated with the significance of RP technology and its related returns. "We're on the verge of a revolution in how things are made" Says Greg Morris, Morris Technologies [25]. Also it expands the relevance of such influence to explicitly cover the SME sector.

The discussed findings help to characterise a leading approach for new opportunities for the RP technology within SMEs. Undoubtedly raising awareness of the importance of human development is a key issue towards an effective decision making about the adoption of RP technology. Moreover there is a need for finding new financial resources alternatives through for example TT or KTP within an SME perspective. Ultimately the reality is not very far from expectation; however there is more work to be done to achieve the envisaged target.

\section{REFERENCES}

[1] Y. Yan, et al., "Rapid prototyping and manufacturing technology: Principle, representative technics, applications, and development trends,” Tsinghua Science and Technology, vol. 14(Supplement 1): pp. 1-12, 2009.

[2] R. Rao and K. Padmanabhan, "Rapid prototyping process selection using graph theory and matrix approach.” Journal of Materials Processing Technology, vol. 194, no.(1-3): p. 81-88, 2007.

[3] S. Vinodh, G. Sundararaj, S. Devadasan, D. Kuttalingam, and D. Rajanayagam, “Agility through rapid prototyping technology in a manufacturing environment using a 3D printer," Journal of Manufacturing Technology Management, vol. 20, no.7: pp. 1023-1041, 2009.

[4] G. Dangayach and S. Deshmukh, “Advanced manufacturing technology implementation: Evidence from Indian small and medium enterprises (SMEs)," Journal of Manufacturing Technology Management, vol. 16, no.5, pp. 483 - 496, 2005.

[5] H. Byun and K. Lee, "A decision support system for the selection of a rapid prototyping process using the modified TOPSIS method,” The International Journal of Advanced Manufacturing Technology, vol. 26: pp. 1338-1347, 2005.

[6] H. Lan, Y. Ding, and J. Hong, "Decision support system for rapid prototyping process selection through integration of fuzzy synthetic 
evaluation and an expert system,” International Journal of Production Research, vol. 43, no.1, pp. 169 - 194, 2005.

[7] R. Cooling. (March 2011). The regions that drive the UK economy. London Press Service, Education [Online]. Available: http://www.londonpressservice.org.uk/lps/tradeindustry/item/128766. html

[8] S. White. (October 2011). Business population estimates for the uk and regions. The Department for Business, Innovation and Skills [Online]. Available:

http://www.fsb.org.uk/pressroom/assets/statistical\%20release\%20bpe $\% 202011 \% 20$ edition.pdf.

[9] G. Verheugen. (2005). The new SME definition. ENTERPRISE AND INDUSTRY PUBLICATIONS-European Commission: EU. [Online]. Available:

http://ec.europa.eu/enterprise/policies/sme/files/sme_definition/sme_u ser_guide_en.pdf

[10] B. Deros, N. Khamis, M. Ab Rahman, and A. Ismail, "A survey on benchmarking understanding and knowledge among malaysian automotive components manufacturing SMEs," European Journal of Scientific Research, vol. 33, no.3, pp. 385-397, 2009.

[11] A. Borille, J. Gomes, R. Meyer, and K. Grote, "Applying decision methods to select rapid prototyping technologies," Rapid Prototyping Journal, vol. 16, no.1, p p. 50 - 62, 2010.

[12] C. López-Gómez and M. Gregory, "Exploring the links between national manufacturing policies and firm level manufacturing strategies," presented at the 16th Annual International EurOMA Conference: Implementation-realizing Operations Management knowledge. Goteborg, Sweden. 2009.

[13] M. Abd Rahman, , N. Mohamed, and R. Hussein, "A case study of barriers to erp adoption in a malaysian medium-sized enterprise," Proceedings of the International Conference on Computer and Network Technology. Singapore: World Scientific Publ Co Pte Ltd. 2010.

[14] G. Cox. (2005). The Cox Review of Creativity in Business: Building on the UK's Strengths. HMSO: London. [Online]. Available: www.hm-treasury.gov.uk/cox

[15] F. Azadivar, Y. Xue, and S. Ordoobadi, "A decision support system for the initiation of technological innovation in small manufacturing enterprises," Industry and Higher Education, vol. 14, no.4, pp. 249-253. 2000.

[16] A. Ahmad, M. Mazhar, and A. Sydney, "Strengthening SMEs through rapid prototyping to meet future challenges why and how?" presented at the 14th Cambridge International Manufacturing Symposium, Centre for International Manufacturing, Institute for Manufacturing: Møller Center, Churchill College , Cambridge, UK. 2009.

[17] C. Harrison. (2010) "Small and medium-sized snterprises (SMEs)". BIS, Editor, South West RDA, Corporate Headquarters. [Online]. Available: economy.swo.org.uk/EasySiteWeb/GatewayLink.aspx?alId=45724

[18] P. McKiernan and C. Morris, "Strategic planning and financial performance in UK SMEs: Does formality matter?” British Journal of Management, vol. 5, pp. S31-S41. 1994.

[19] H. Carey, C. Vogel, J. Cagan, and L. Weingart, Integrating Design Thinking into the Strategic Planning Phase of Product Development. Google scholar [Online]. Available: http://citeseerx.ist.psu.edu/viewdoc/download?doi=10.1.1.201.1979\& rep=rep1\&type $=$ pdf.

[20] I. Pearce, A. John, and R. Robinson, "A measure of ceo social power in strategic decision making,” Strategic Management Journal, vol. 8, no.3, pp. 297-304. 1987.

[21] J. Kargar and J. Parnell, "Strategic planning emphasis and planning satisfaction in small firms: an empirical investigation," Journal of Business Strategies, vol.13, no.1, pp. 42-64. 1996.

[22] L. Raymond and A. Croteau, "Enabling the strategic development of SMEs through advanced manufacturing systems," Industrial Management and Data Systems, vol. 106, no.7, pp. 1012-32. 2006.
[23] N. O'Regan and G. Kling, "Technology outsourcing in manufacturing small and medium sized firms: another competitive resource?” $R \& D$ Management, vol. 41, no.1, pp. 92-105. 2011.

[24] U. Bititci and A. Ates, "The appropriateness of current intervention policy patterns and delivery mechanisms to address the manufacturing SME needs in Europe,” presented at the 14th Cambridge International Manufacturing Symposium, Centre for International Manufacturing, Institute for Manufacturing: Møller Center, Churchill College Cambridge, UK. 2009.

[25] J. Ogando. (2007). Rapid Manufacturing's Role in the Factory of the Future. [Online]. Available: http://www.designnews.com/article/7233-Rapid_Manufacturing_s_R ole_in_the_Factory_of_the_Future.php.

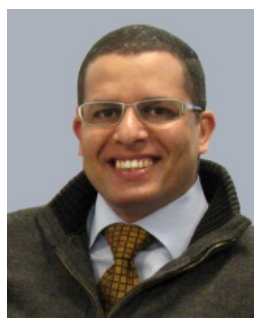

Ahmed M. Romouzy-Ali. is a Postgraduate Researcher $\mathrm{PhD}$ in the School of Design, Engineering and Computing at Bournemouth University, Poole, United Kingdom. Also he is an Associate Lecturer in the Industrial Design Department, Faculty of Applied Arts at Helwan University, Giza, Egypt. He holds M.Sc. degree in Industrial Design from the Faculty of Applied Arts at Helwan University. His main areas of academic and research interest are Rapid Prototyping Technology, New Product Development, Product/Industrial Design Practises, Technology Transfer, Knowledge Transfer Partnership and High Value Manufacturing. His research and lectures cover such disciplines.

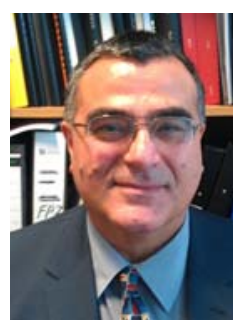

Siamak Noroozi, Professor. He received his $\mathrm{PhD}$ from Sheffield University in 1986 in the area of Finite Element Analysis coupled with Boundary Element Analysis. He currently holds the Chair in Advanced Technology at Bournemouth University. His research interests are Finite Element Analysis, Boundary Element Analysis, biomechanics, condition monitoring, general stress analysis, photoelasticity, alternative numerical analysis, composite technology

and aeroelasticity.

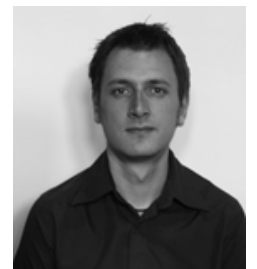

Philip Sewell, Dr. He received his BEng degree in mechanical engineering from the University of the West of England in 1999 and a PhD in the field of Prosthetic Design in 2003. He is currently employed as a Senior Academic in Design Simulation at Bournemouth University. His research interests include the design of novel tools for prosthetic fitting, the development of techniques to determine prosthetic interfacial pressure distributions, and experimental and numerical stress analysis.

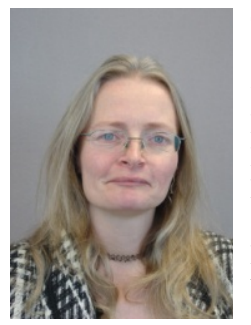

Tania Humphries-Smith, Dr. She is Associate Dean (Design and Engineering) at Bournemouth University whose teaching areas are Engineering and Product Design. She was in professional practice as a Product Designer before entering Academia. She is also a Member of the Institution of Engineering Designers and Member of Council, as well as a Chartered Engineer. Her research activities are in the areas of both sustainable product design, specifically, the social

aspects of sustainable design and design education. She has published papers in design education since 1998. 